\title{
Paralleling the Quality and Economy of Levofloxacin Hemihydrate and Cefuroxime Axetil Tablets
}

\author{
Atmaram Pawar ${ }^{1, *}$, Mahesh Chainpure ${ }^{2}$, Vividha Dhapte-Pawar ${ }^{1}$ \\ ${ }^{1}$ Department of Pharmaceutics, Poona College of Pharmacy, Bharati Vidyapeeth University, Erandwane, Pune, Maharashtra, INDIA. \\ ${ }^{2}$ Department of Drug Regulatory Affairs, Poona College of Pharmacy, Bharati Vidyapeeth University, Erandwane, Pune, Maharashtra, \\ INDIA.
}

\begin{abstract}
Aim/Background: The Government of India has initiated different regulations and provisions to provide low cost medicines at affordable rates than the high cost medicines. The government has initiated Jan Aushadhi stores in every city and village of India with the motto of promoting quality medicines for all at economic price. Improving the public perception and addressing their doubts regarding the quality and efficacy of low-cost medicines is a big challenge in this endeavour. Materials and Methods: In the present study, we have compared the low, medium and high cost medicines of biopharmaceutical classification system class I drug, levofloxacin hemihydrate and biopharmaceutical classification system class II drug, cefuroxime axetil, in order to verify their quality and efficacy. Existing low cost and medium cost brands of these drugs were selected and compared with their respective high cost products as per quality standards of Indian Pharmacopoeia viz. weight variation, friability, disintegration, assay and in vitro dissolution study specified in general and individual monographs. Moreover, ex vivo permeability and antimicrobial activities were assessed while comparing the efficacy of these products. Results: Findings from these studies revealed no significant differences between the efficacy of low cost, medium cost and high cost products. All products complied with the Indian Pharmacopoeia tests along with the comparable ex vivo permeation and antimicrobial activities for both the drugs. Conclusion: This study revealed that the low cost and medium cost tablets of levofloxacin hemihydrate and cefuroxime axetil can be used at par with the costlier tablets of same drugs.
\end{abstract}

Key words: Levofloxacin hemihydrate, Cefuroxime axetil, Generic, Microbial assay, Pharmacopoeial evaluation.

\section{INTRODUCTION}

World Health Organization (WHO) and global drug regulatory agencies support the use of generic drugs (affordable alternative to innovator and branded medicines) to reduce the expenditure on high cost medicine significantly. ${ }^{1}$ Especially in developing nations like India, government endorses the use of generic medicines to reach every needy person and improve the health of nation. Diverse regulatory agencies have different requirements for registration and promotion of generic drugs. Generic products have saved almost $\$ 1.7$ trillion USD in the US healthcare system (2002-2011). If two products are pharmaceutically equivalent and their effect with respect to safety and efficacy are essentially same without direct proof, then it is therapeutically same as per WHO. Netherlands, Germany, Canada and UK have $20 \%, 30 \%, 50-30 \%, 80 \%$ higher price of branded drugs than generics, respectively. Promotion of economic drug products largely depends on government policies and

India, in context of generic pharmaceutical product manufacturing, by volume stands at third rank. Till 2020, the Indian pharmaceutical market is expected to grow $\$ 72$ billion USD sale from $\$ 11$ billion USD. programs. $^{2}$
Submission Date: 29-05-2020; Revision Date: 25-08-2020; Accepted Date: 07-10-2020

DOI: 10.5530/ijper.55.1.16 Correspondence: Dr. Atmaram Pawar Professor of Pharmaceutics, Bharati Vidyapeeth University, Poona College of Pharmacy, Pune-411038, Maharashtra, INDIA.

Phone: +91 020-25437237

Email id: p_atmaram@ rediffmail.com

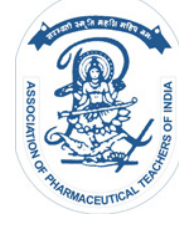

www.ijper.org 
In terms of exports, India stands at $17^{\text {th }}$ rank. India exports generic products to more than 200 countries across the globe which include highly regulated markets of USA, Europe, Japan and Australia. ${ }^{3}$ Central Drug Standard Control Organization (CDSCO), the drug regulatory authority of India, monitors the filing and approval process for drug and drug products. Drugs which are approved and being used for several years in other countries may be waived off the clinical trials ${ }^{4}$ by the Central Licensing Authority (CLA) i.e. Drug Controller General of India (DCGI) as per the New Drugs and Clinical Trial Rules, 2019 (NDs and CTs Rules, 2019) under special conditions. Earlier to this, applicants who wished to file drug product used to apply along with requisite fee. Preliminary evaluation of application was done; if it was acceptable then it underwent regulatory evaluation or the applicant had to re-file again. ${ }^{3,4}$ After all the satisfactory data evaluation, applicant had to request for on-site facility inspection. If it was successful, then applicant was granted approval for manufacturing drug products. Data was compiled in the form of common technical document (CTD) prior to 2016. Recently CDSCO implemented the online Sugam portal for the marketing authorization application. ${ }^{5}$ In recent times, stringent regulations regarding drugs and medical devices are becoming essential to achieve the aim of providing modern healthcare access to public at affordable rates. Government of India is striving towards 'affordable healthcare for all' and to achieve this goal, regulations for controlling drugs and medical devices are framed judiciously. Since April 2017, bioequivalence studies for BCS Class II and IV drugs are made compulsory in India to assure the quality of affordable medicines which will be made available to people. ${ }^{6} \mathrm{~A}$ well achieved milestone towards this is the availability of medicines in Jan Aushadhi stores at much economic rates. ${ }^{7}$ In addition, DCGI in June 2018 suggested segregation of generic medicines from branded ones and stocking them in a manner that is easily visible to consumers. ${ }^{8}$ Biopharmaceutical Classification System (BCS) of drugs have been used as logical tool for design and testing of oral formulations, particularly tablets. Drug as per its solubility and permeability behaviour differ significantly in a way to produce designed therapeutic outcomes. Tablets of BCS II and IV drugs have been reported to show variation in formulation as well as pharmaceutical performance when manufactured by various industries. ${ }^{9,10}$ Therefore, in the present study class I category drug with minimum variations in yielding therapeutic outcome and BCS II drug with marked variation in drug performance, in terms of bioavailability were selected for the study.
Levofloxacin, BCS I category drug, a synthetic fluoroquinolone antibacterial agent inhibits the super coiling activity of bacterial DNA gyrase, halting DNA replication. It has excellent antibacterial activity against many clinically significant pathogens such as Pseudomonas aeruginosa and Escherichia coli. Levofloxacin with 4-8 h halflife is known for rapid and almost complete absorption from the gastrointestinaltract (GIT), reaching peak plasma concentrations approximately $1-3 \mathrm{~h}$ after oral administration. ${ }^{11,12}$

BCS II type drug, cefuroxime is a broad-spectrum cephalosporin antibiotic resistant to beta-lactamase. It has excellent antimicrobial activity against Micrococcus luteus and Kocuria rbizophila. Cefuroxime, like penicillin, is a beta-lactam antibiotic that binds to specific penicillinbinding proteins (PBPs) located inside the bacterial cell wall and inhibits the third and last stage of bacterial cell wall synthesis. Cell lysis is then mediated by bacterial cell wall autolytic enzymes such as autolysins wherein cefuroxime interferes with an autolysin inhibitor. After oral administration, cefuroxime is absorbed from the GIT and rapidly hydrolysed by non-specific esterase's in the intestinal mucosa and blood. It is subsequently distributed throughout the extracellular fluids in adults. $^{13,14}$

The present study was aimed to compare the tablets having significant difference in retail prices of levofloxacin hemihydrate (LH) and cefuroxime axetil (CA) by using pharmacopoeial evaluation tests, ex vivo permeability studies and antimicrobial activity in order to establish similarity or difference between the quality and efficacy of tablets with different prices. This study will help in building public confidence and raising social awareness about affordable medicines.

\section{MATERIALS AND METHODS}

\section{Materials}

Levofloxacin hemihydrate (LH) and cefuroxime axetil (CA) were procured from Micro Labs, Bengaluru and Wockhardt Ltd., Aurangabad, respectively. The film coated tablets of different brands, LH high cost (LH-HC) tablet 500, LH medium cost (LH-MC) tablet 500 were purchased from local retail pharmacies in Pune, India. LH low cost (LH-LC) tablets 500 were obtained from Jan Aushadhi (JA) store, Pune, India. Film coated, CA high cost (CA-HC) tablet 250/500 and CA medium cost (CA-MC) tablet 250/500 and CA low cost (CA-LC) tablets $250 / 500 \mathrm{mg}$ were purchased from local retail pharmacies and Jan Aushadhi (JA) store, Pune, India, respectively. Tablets with their details are mentioned in Table 1. Acetonitrile of HPLC grade was purchased 


\begin{tabular}{|c|c|c|c|c|c|c|}
\hline & $\begin{array}{c}\text { Film coated } \\
\text { Tablet }\end{array}$ & Strength & $\begin{array}{l}\text { Batch } \\
\text { Number }\end{array}$ & $\begin{array}{c}\text { Manufacturing } \\
\text { Date }\end{array}$ & $\begin{array}{l}\text { Expiry } \\
\text { Date }\end{array}$ & $\begin{array}{c}\text { Maximum } \\
\text { Retail Price } \\
\text { (Rs.) per tablet }\end{array}$ \\
\hline \multirow{3}{*}{ Levofloxacin hemihydrate } & LH-HC-500 & $500 \mathrm{mg}$ & AEP 81339 & $11 / 2018$ & $10 / 2021$ & 8.48 \\
\hline & LH-MC-500 & $500 \mathrm{mg}$ & ALD810A & $9 / 2018$ & $8 / 2019$ & 8.48 \\
\hline & LH-LC-500 & $500 \mathrm{mg}$ & GT171425 & $10 / 2017$ & $09 / 2020$ & 2.6 \\
\hline \multirow{6}{*}{ Cefuroxime axetil } & CA-HC-250 & $250 \mathrm{mg}$ & MA227 & $10 / 2018$ & $9 / 2020$ & 52.5 \\
\hline & CA-MC-250 & $250 \mathrm{mg}$ & LOB870A & $10 / 2018$ & $09 / 2020$ & 18.8 \\
\hline & CA-LC-250 & $250 \mathrm{mg}$ & СТ8044 & $05 / 2018$ & $04 / 2021$ & 5.6 \\
\hline & CA-HC-500 & $500 \mathrm{mg}$ & MA529 & $05 / 2018$ & $04 / 2020$ & 94.1 \\
\hline & CA-MC-500 & $500 \mathrm{mg}$ & LOC804A & $04 / 2018$ & $03 / 2020$ & 32.66 \\
\hline & CA-LC-500 & $500 \mathrm{mg}$ & GT171427 & $10 / 2017$ & $09 / 2020$ & 2.68 \\
\hline
\end{tabular}

$\# L H, C A, H C, M C$ and LC stands for Levofloxacin hemihydrate, Cefuroxime axetil, high cost, medium cost and low cost respectively.

from Sigma Aldrich, India. All other chemical and reagents used were of analytical grade, purchased from Merck, India. Gram-negative bacteria Escherichia coli (ATCC-10536) and gram-positive bacteria Micrococcus luteus (ATCC-10786) were used as test micro-organisms for the antimicrobial study of LH and CA, respectively. Muller-Hinton agar was used for antimicrobial assay.

\section{Development of standard curve}

Drug standard curves were developed in various buffers $(\mathrm{pH} 1.2$, acetate buffer $\mathrm{pH} 4.5$ and phosphate buffer $\mathrm{pH}$ 6.8) and water using UV-Vis spectrophotometer. Accurately weighed amount of drug (LH / CA) was dissolved in buffers or water, sonicated if necessary. Further dilutions were made using respective solvents to obtain stock and working standard solutions in the concentration range of 2 to $18 \mu \mathrm{g} / \mathrm{ml}$ for $\mathrm{LH}$ and 4 to $20 \mu \mathrm{g} / \mathrm{ml}$ for CA. ${ }^{15,16}$ Absorbance maxima $\left(\lambda_{\max }\right)$ were measured using UV-Visible spectrophotometer (JASCO-V630). The absorbance values of all working standard solutions were measured at their respective absorbance maxima. All the experiments were done in triplicates $(n=3)$. Linearity was established over the entire concentration range by plotting graph of absorbance versus corresponding concentrations. The data were statistically evaluated using linear regression analysis.

\section{Biopharmaceutical classification system (BCS) solubility}

The BCS solubility of a drug is determined by dissolving the highest unit dose of drug in $250 \mathrm{ml}$ of aqueous media throughout the $\mathrm{pH}$ range 1.0 to 6.8. As the highest doses of LH and CA is $750 \mathrm{mg}$ and $500 \mathrm{mg}$, respectively, the same were considered for this study. Accurately weighed drugs were added to above solvents, under continuous agitation for $24 \mathrm{~h}$ using Brunswick scientific Excella incubator shaker at $37 \pm 1^{\circ} \mathrm{C}$. Later the solution was filtered through $0.45 \mu$ Whatman filter paper and suitable dilutions were made. Quantity of solubilised drug was determined using UV-Vis spectrophotometer at their respective $\lambda_{\text {max }}(n=3) \cdot{ }^{17,18}$

\section{Evaluation tests for tablets}

\section{Hardness}

Six tablets of LH / CA (in respective strengths) were used for hardness testing using a Monsanto Hardness Tester.

\section{Weight Variation}

Randomly 20 film coated tablets of LH / CA (in respective strengths) were taken and weighed individually for calculating average weight. The deviation of individual weights from the average weight was determined as per Indian Pharmacopoeia (IP) 2018 procedure. ${ }^{19}$

\section{Disintegration test}

The disintegration test was performed on six units of $\mathrm{LH}$ / CA (in respective strengths) as per IP 2018 procedure. The disintegration time in water was measured using Electro lab DT1000 disintegration test apparatus at $37 \pm 1^{\circ} \mathrm{C} .{ }^{19}$

\section{Friability}

LH / CA tablets equivalent to $6.5 \mathrm{~g}$ or nearest higher weight were considered and initial weight was recorded. Friability was performed using friability tester by rotating the respective tablets in drum for 100 rotations followed by dedusting and recording of final weight. ${ }^{19}$ Percent friability was calculated using following equation

$$
\% \text { Friability }=\frac{\text { Initial weight }- \text { Final weight }}{\text { Initial weight }} \times 100
$$




\section{Assay of LH and CA Preparation of test solution}

For LH, 20 tablets were weighed and powdered using mortar pestle. Accurate quantity of powder containing $100 \mathrm{mg}$ of levofloxacin was dispersed in $100 \mathrm{ml} 0.1$ $\mathrm{M} \mathrm{HCl}$ followed by filtration and subsequent dilution with water. Randomly 10 tablets of CA were dispersed in $0.2 \mathrm{M}$ ammonium dihydrogen orthophosphate with previously adjusted $\mathrm{pH}$ to 2.4 using orthophosphoric acid (10 $\mathrm{ml}$ per $\mathrm{g}$ of the stated content of cefuroxime). Sufficient methanol was immediately added to produce a solution containing the equivalent of $0.5 \% \mathrm{w} / \mathrm{v}$ of cefuroxime and shaken vigorously. Obtained filtrate was further diluted with sufficient mobile phase to produce a solution containing $0.025 \% \mathrm{w} / \mathrm{v}$ of CA. ${ }^{19}$

\section{Preparation of reference solution (RS)}

A $0.1 \% \mathrm{w} / \mathrm{v}$ solution of LH RS was prepared by dissolving levofloxacin in $0.1 \mathrm{M} \mathrm{HCl}$. From above solution, $5 \mathrm{ml}$ volume was withdrawn and diluted to $50 \mathrm{ml}$ with water. $0.03 \% \mathrm{w} / \mathrm{v}$ solution of CA RS was prepared in the mobile phase The column used for levofloxacin and cefuroxime was RP-C 18 Column $(250 \times 4.6 \mathrm{~mm}, 5 \mu)$ with methanol: $0.2 \mathrm{M}$ ammonium dihydrogen orthophosphate $(38: 62 \%$ $\mathrm{v} / \mathrm{v})$ and $1 \mathrm{M}$ ammonium acetate: acetonitrile $(85: 15 \%$ $\mathrm{v} / \mathrm{v})$, respectively as mobile phases. Injection volume $(20 \mu \mathrm{l})$ was used at the flow rate of $1.2 \mathrm{ml} / \mathrm{min}(293 \mathrm{~nm})$ and $1 \mathrm{ml} / \mathrm{min}(278 \mathrm{~nm})$ for $\mathrm{LH}$ and CA, respectively. ${ }^{19}$

\section{In vitro dissolution test}

Dissolution test was carried using 6 units of the respective dosage form as per IP 2018. The test was carried out using Electrolab Dissolution test apparatus (TDT-06L). As per IP, the dissolution media specified in individual monograph for $\mathrm{LH}$ and $\mathrm{CA}$ is $0.01 \mathrm{M} \mathrm{HCl}$ and $0.1 \mathrm{M}$ $\mathrm{HCl}$, respectively. Additionally, this study was also performed with $\mathrm{pH} 1.2$, acetate buffer $\mathrm{pH} 4.5$, phosphate buffer $\mathrm{pH} 6.8$ and distilled water as dissolution medium in accordance with the USFDA Guidance for Industry ${ }^{19}$ in Electrolab Dissolution test apparatus (Paddle type). Volume of media was $900 \mathrm{ml}$ wherein $5 \mathrm{ml}$ samples were withdrawn at 5, 10,15,30 and 45 min time points under sink conditions. RPM was maintained at 100 and 50 for $\mathrm{LH}$ and $\mathrm{CA}$, respectively at $37 \pm 5^{\circ} \mathrm{C}$. Acceptance criteria are not less than $70 \%$ of stated amount for both the drugs. After each time points, the aliquot was taken and filtered through $0.45 \mu$ Whatman paper to remove the undissolved particles. Further dilutions were made and subjected to UV-Vis spectrometer for measuring the drug release at $293 \mathrm{~nm}$ and $281 \mathrm{~nm}$, respectively. $16,17,19-21$

\section{Ex vivo permeation study}

Ex vivo permeation study was performed using everted gut sac technique. ${ }^{21,22}$ The freshly cut, goat gut was collected from local slaughter house, Pune and placed in a mixture of Krebs-Ringer phosphate solution and isopropyl alcohol $(70: 30 \mathrm{v} / \mathrm{v})$. The gut was then washed with cold oxygenated saline solution and sectioned into $10 \mathrm{~cm}$ small portions. One side of the gut sac was tied using a thread. With the help of glass rod, gut sac was everted by sliding it over the opposite side so that the surface was inside out. Sticky matter was cleaned using cold Ringer's solution. Phosphate buffer saline $\mathrm{pH} 7.4$ was filled in the gut sac and tied from the other end. This sac was placed in the flask of dissolution apparatus containing $900 \mathrm{ml}$ phosphate buffer saline $\mathrm{pH} 7.4$ at $37 \pm 1^{\circ} \mathrm{C}$ at the aeration rate of $1-2$ bubbles per second. Later, LH and CA tablets were placed in the dissolution apparatus. This study was performed using same machine parameters followed for dissolution test. Samples were withdrawn at single time point of 3 $\mathrm{h}$ from the dissolution flask and gut sac. Further drug release and amount permeated was calculated using UV-Vis spectrophotometer at absorbance maxima $\left(\lambda_{\max }\right)$ $293 \mathrm{~nm}$ and $281 \mathrm{~nm}$, respectively for LH and CA. This procedure was followed to assess the simultaneous permeation of the drug post tablet disintegration and dissolution. ${ }^{23,24}$

\section{Microbial assay}

Microbial assay was performed in autoclaved MüllerHinton Agar media by well diffusion method. ${ }^{21,25}$ Autoclaved media was poured in the sterile Petri plates aseptically and kept for solidification. Post solidification, test cultures were spread on the media with the help of glass spreader. Subsequently, wells were drilled with the help of sterile cork borer. Antimicrobial study was performed at 5, 10,15 mg/ml LH and 50,100,150 $\mathrm{g} / \mathrm{ml}$ CA concentrations. ${ }^{10,12}$ Various drug concentrations of LH and CA products were added in respective, labeled wells, aseptically. After diffusion, these inoculated and supplemented plates were incubated at $35 \pm 2{ }^{\circ} \mathrm{C}$ aerobically for $24 \mathrm{~h}$. Following incubation, the area of inhibition $\left(\mathrm{mm}^{2}\right)$ around the well was calculated and compared using a concentration versus area of inhibition graph.

\section{RESULTS AND DISCUSSION}

LH and CA were selected as prototype drugs from BCS class I and class II categories, respectively for present study. From market survey, it was found that 
comparatively very less number of tablet type products are available in market which contain LH and CA. Price variation for $\mathrm{LH}$ products was comparatively less as it comes under National Pharmaceutical Pricing Authority (NPPA). ${ }^{22,23}$ However, for CA products, significant cost difference was found. Thus, we selected LH and CA tablets manufactured by different companies with cost difference viz. high cost (LH-HC) tablets 500, (CA-HC) tablets 250/500; Medium cost (LH-MC) tablet 500, (CA-MC) tablet 250/500 from retail pharmacies and low cost (LH-LC) tablets 500, (CA-LC) tablets 250/500 mg from Jan Aushadhi (JA) stores, respectively for our research work.

\section{UV spectrometric calibration curve}

The calibration curve was developed in four media, as recommended by USFDA guidance ${ }^{20}$ for routine drug analysis in dissolution study as well as other evaluation tests such as solubility and permeation study in the range of $2-18 \mu \mathrm{g} / \mathrm{ml}$ and $4-20 \mu \mathrm{g} / \mathrm{ml}$ for $\mathrm{LH}$ and CA, respectively. The data were statistically evaluated using linear regression analysis with a regression coefficient 0.99 .

\begin{tabular}{|c|c|c|}
\hline \multirow[b]{2}{*}{$\begin{array}{l}\text { Medium } \\
\text { Strength }\end{array}$} & \multicolumn{2}{|c|}{ Solubility $(\mathrm{mg} / 250 \mathrm{ml})^{*}$} \\
\hline & $\begin{array}{c}\text { Levofloxacin } \\
\text { hemihydrate (LH) } \\
750 \mathrm{mg}\end{array}$ & $\begin{array}{c}\text { Cefuroxime } \\
\text { axetil (CA) } \\
500 \mathrm{mg}\end{array}$ \\
\hline Water & $651.70 \pm 0.08$ & $76.80 \pm 0.085$ \\
\hline $0.1 \mathrm{M} \mathrm{HCl}(\mathrm{pH} 1.2)$ & $673.10 \pm 0.038$ & $107.00 \pm 0.38$ \\
\hline Acetate Buffer ( $\mathrm{pH} 4.5)$ & $676.80 \pm 0.24$ & $274.30 \pm 0.24$ \\
\hline Phosphate Buffer ( $\mathrm{pH} 6.8$ ) & $692.80 \pm 0.08$ & $303.00 \pm 0.08$ \\
\hline
\end{tabular}

\# BCS stands for Biopharmaceutical Classification System.

$*$ Results are expressed as mean $\pm S D$, where $n=3$. SD: Standard deviation

\section{BCS solubility}

As per USFDA guidance, solubility of a drug substance is considered in the volume less than or equal to $250 \mathrm{ml}^{20}$ Volume of $250 \mathrm{ml}$ is equal to 8 ounces as it is considered that tablet is taken with 1 glass of water, equivalent to 8 ounces.

For BCS solubility studies of LH and CA, $750 \mathrm{mg}$ and $500 \mathrm{mg}$ were the highest strengths, respectively performed using $250 \mathrm{ml}$ in various media ranging from $\mathrm{pH} 1.0$ to 6.8. Highest dose solubility (more than $90 \%$ of drug) for $\mathrm{LH}$ was found to be $692 \mathrm{mg}$ in $250 \mathrm{~mL}$ phosphate 6.8 buffer (Table 2). Data revealed its high solubility in $\mathrm{pH} 4.5$ and $\mathrm{pH} 6.8$ when compared to water and $\mathrm{pH}$ 1.2. Almost $50 \%$ of $\mathrm{CA}$ was solubilised at higher $\mathrm{pH}$ whereas less solubilisation was observed at lower $\mathrm{pH}$ (Table 2). LH belongs to BCS class I (high solubility) category. ${ }^{24,26} \mathrm{CA}$ belongs to BCS class II (low solubility) category. ${ }^{27}$ For $\mathrm{CA}$, variation in solubility was observed reflecting $\mathrm{pH}$ dependant solubility.

\section{Evaluation tests for tablets}

As summarized in Table 3, all the tablets tested were within the limits specified for the uniformity of weight by IP. However, they exhibited different hardness which is known to impact disintegration and dissolution behaviour. When evaluated, the effect of hardness was observed as the tablet with low hardness exhibited shorter disintegration time and vice versa. Yet, all the tablets disintegrated within the time specified by the IP, thereby passing the test. ${ }^{19}$

\section{Assay of tablets by HPLC method}

As per IP, tablet should contain not less than $90 \%$ and not more than $110 \%$ of stated amount of drug ( $\mathrm{LH}$ as well as CA). ${ }^{19}$ The drug content determined using RP-HPLC method revealed the compliance within IP

\begin{tabular}{|c|c|c|c|c|c|c|c|}
\hline Tablet & $\begin{array}{l}\text { Weight } \\
\text { variation* (ma) }\end{array}$ & \multicolumn{2}{|c|}{ Thickness/width* $(\mathrm{mm})$} & $\begin{array}{c}\text { Hardness* } \\
\left(\mathrm{kg} / \mathrm{cm}^{2}\right)\end{array}$ & Friability* (\%) & Disintegration & Drug \\
\hline LH- HC -500 & $686 \pm 34.3$ & $5.00 \pm 0.069$ & $17.01 \pm 0.009$ & $11 \pm 0.81$ & $0.01 \pm 0.0029$ & $3.34 \pm 0.055$ & $99.1 \pm 0.02$ \\
\hline LH-MC-500 & $695 \pm 34.75$ & $4.63 \pm 0.028$ & $18.31 \pm 0.026$ & $9 \pm 0.47$ & $0.02 \pm 0.0036$ & $3.8 \pm 0.047$ & $98.1 \pm 0.036$ \\
\hline LH-LC -500 & $942 \pm 47.1$ & $5.67 \pm 0.255$ & $20.03 \pm 0.024$ & $7 \pm 0.47$ & $0.04 \pm 0.0039$ & $3.1 \pm 0.013$ & $98.2 \pm 0.025$ \\
\hline $\mathrm{CA}-\mathrm{HC}-500$ & $924.25 \pm 46.21$ & $6.32 \pm 0.020$ & $18.03 \pm 0.023$ & $10 \pm 0.47$ & $0.01 \pm 0.0021$ & $1.36 \pm 0.023$ & $99.98 \pm 0.02$ \\
\hline CA-MC -500 & $943.2 \pm 47.16$ & $4.89 \pm 0.020$ & $18.25 \pm 0.018$ & $11 \pm 0.47$ & $0.01 \pm 0.0032$ & $3.2 \pm 0.041$ & $97.41 \pm 0.01$ \\
\hline CA-LC -500 & $974.5 \pm 48.71$ & $5.26 \pm 0.024$ & $21.02 \pm 0.012$ & $12 \pm 0.47$ & $0.04 \pm 0.0023$ & $5.6 \pm 0.032$ & $95.52 \pm 0.04$ \\
\hline $\mathrm{CA}-\mathrm{HC}-250$ & $462 \pm 23.1$ & $5.27 \pm 0.047$ & $15.11 \pm 0.061$ & $7 \pm 0.47$ & $0.02 \pm 0.0012$ & $1.5 \pm 0.054$ & $99.93 \pm 0.01$ \\
\hline CA-MC -250 & $470 \pm 23.5$ & $4.73 \pm 0.066$ & $14.70 \pm 0.083$ & $8 \pm 0.47$ & $0.01 \pm 0.0042$ & $2 \pm 0.012$ & $97.41 \pm 0.02$ \\
\hline CA-LC -250 & $630 \pm 31.5$ & $5.16 \pm 0.065$ & $16.49 \pm 0.066$ & $10 \pm 0.47$ & $0.03 \pm 0.0026$ & $2.3 \pm 0.066$ & $97.27 \pm 0.066$ \\
\hline
\end{tabular}

\# LH, CA, HC, MC and LC stands for Levofloxacin hemihydrate, Cefuroxime axetil, high cost, medium cost and low cost, respectively.

*Results are expressed as mean $\pm S D$, where $n=3$. SD: Standard deviation 
limits. Hence all the tablets passed the limits specified in IP as per Table 3.

\section{In vitro dissolution study}

All the tablets were found to release more than $70 \%$ of total drug content which complies with the IP limits for dissolution test as specified in individual monographs of $\mathrm{LH}$ and CA. ${ }^{19}$ Additionally, dissolution testing was performed as per USFDA guidance (multimedia dissolution test). ${ }^{20}$

The data revealed $\mathrm{pH}$ independent drug release for $\mathrm{LH}$ tablets which can be attributed to its $\mathrm{pH}$ independent high solubility. The dissolution graphs for LH 500 are shown in Figure 1 and CA 250 and 500 in Figures 2 and 3 , respectively. Similarity factor (f2) calculated for comparing the dissolution profiles of medium cost and low-cost tablets with high cost tablets, revealed the similarity of drug release profile amongst all (Table 4). Low-cost tablets exhibited slight lower release than the medium cost and high cost tablets however; the difference was not significant $(p>0.05)$. All low-cost tablets complied with the IP limits.

\section{Ex vivo permeation}

Bioavailability is commonly known as extent and rate at which drug reaches systemic circulation. ${ }^{26}$ Intestinal permeability is principal determinant of drug absorption post oral administration. Transport across the intestinal barrier is a perquisite for clinical effects of most drugs and intestinal permeability is used for classifying drugs in the biopharmaceutical classification system (BCS). Numerous methods have been used to evaluate intestinal absorption of drugs. Ex vivo and in situ models in small animals are also widely used when there is a good agreement between intestinal permeability. Ex vivo methods like everted gut sac techniques provide theoretical means of estimating human intestine absorption. ${ }^{28}$ For LH, amount of dissolved and permeated drug was same. In case of CA, there was difference in the amount of dissolved and permeated drug (Table 5). This was in accordance to their respective BCS class. LH tablets revealed the identical correlation between dissolution and permeation studies which underlined the solubility dependent drug absorption for all brands of LH irrespective of their price. As CA belongs to BCS class II, various brands of CA were unable to illustrate solubility dependent drug absorption.

\section{Microbial assay}

Microbial assay of an antibiotic is the key measure of its effectiveness. ${ }^{12,25}$ Zone of inhibition around the well is directly proportional to the effectiveness of drug in a specific test microbial strain. The data revealed that effectiveness of both drugs is concentration dependant. Also, there was no significant difference observed for the tablets of various brands when data was statistically
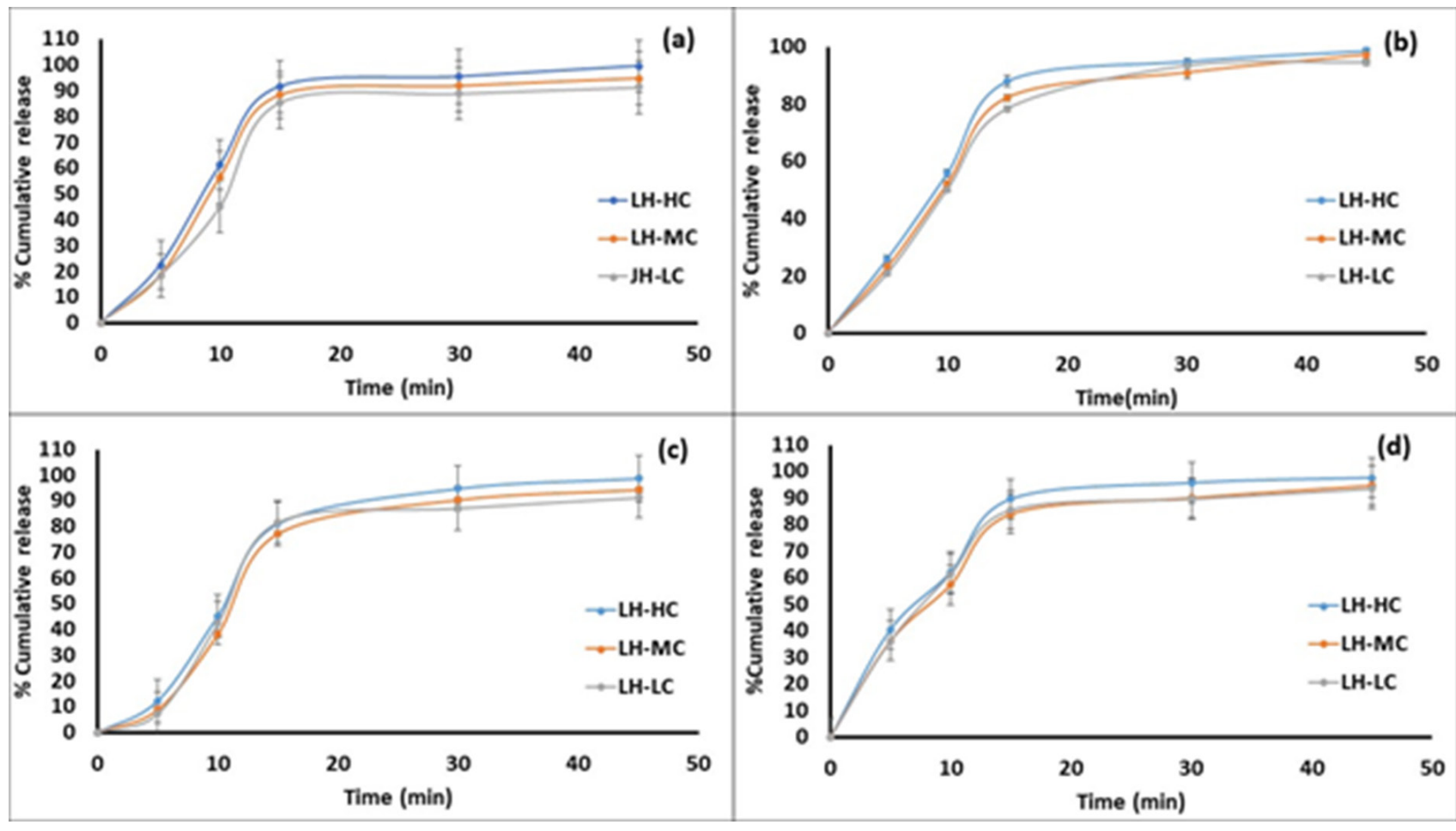

Figure 1: Dissolution profiles of different LH 500 brands in (a) water, (b) $0.01 \mathrm{M} \mathrm{HCl}$ (c) acetate buffer pH 4.5 and (d) phosphate buffer pH 6.8. 


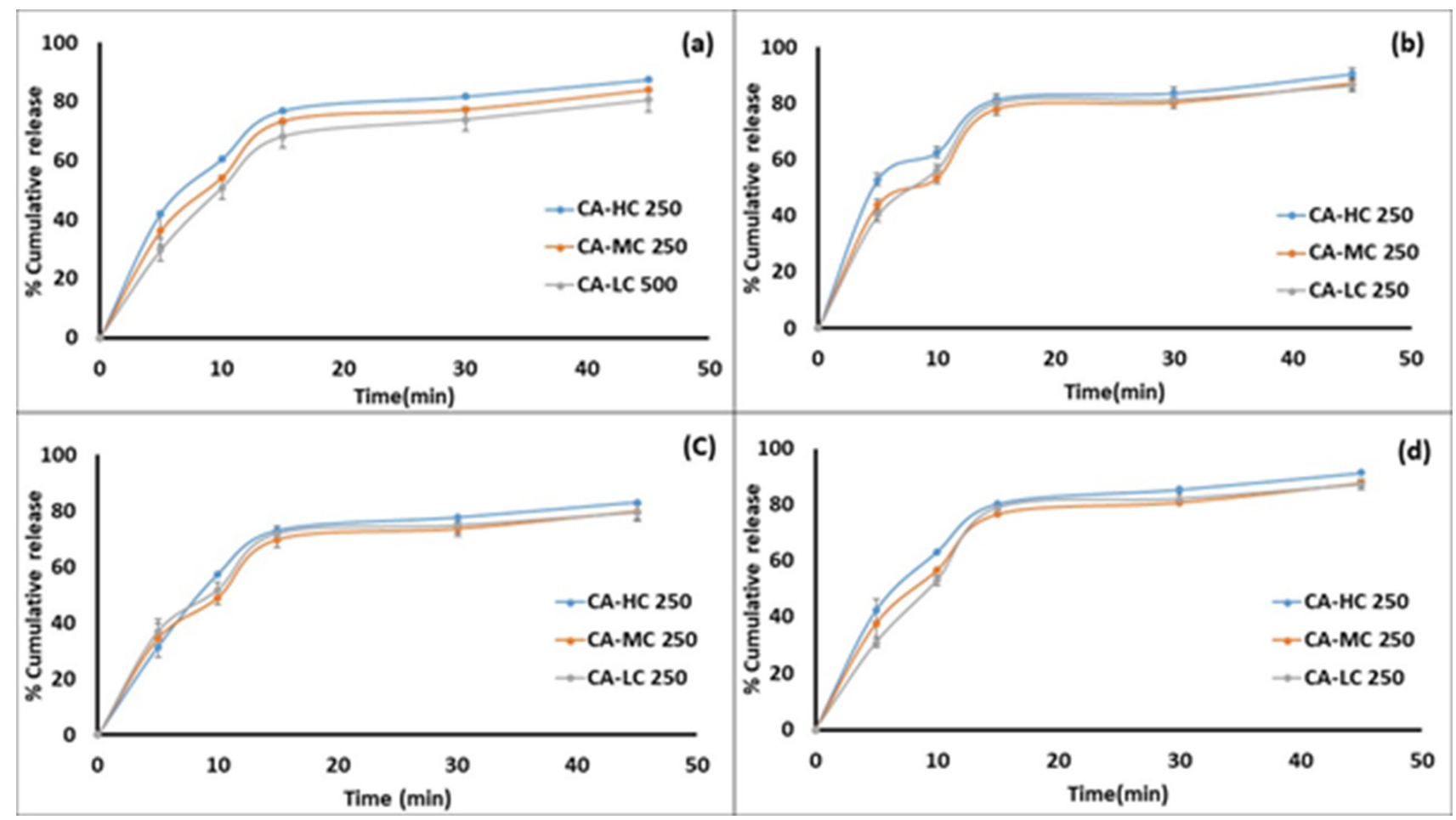

Figure 2: Dissolution profiles of different CA 250 brands in (a) water, (b) $0.1 \mathrm{M} \mathrm{HCl}$ (c) acetate buffer pH 4.5 and (d) phosphate buffer $\mathrm{pH} 6.8$.

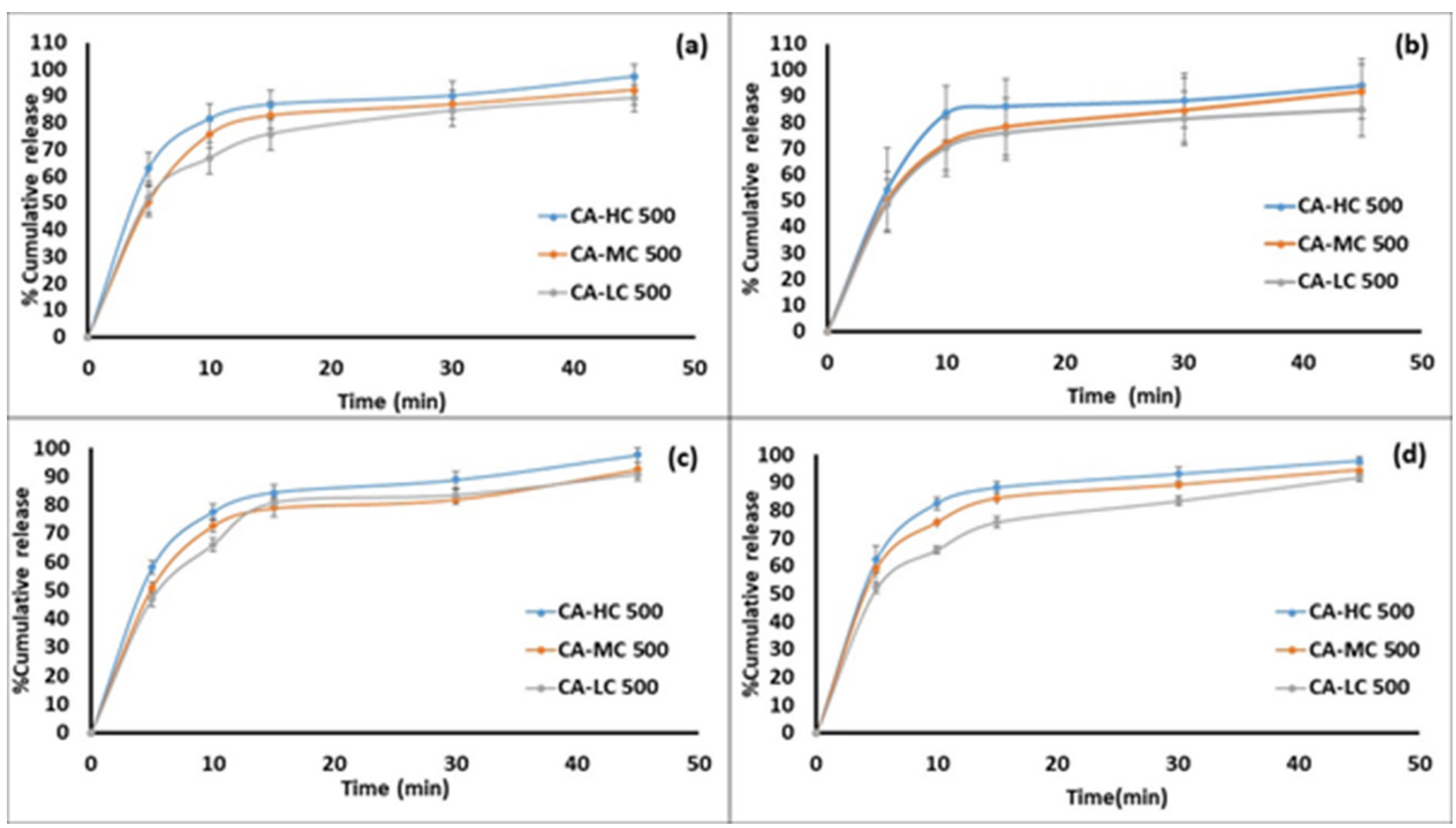

Figure 3: Dissolution profiles of different CA 500 brands in (a) water, (b) $0.1 \mathrm{M} \mathrm{HCl}$ (c) acetate buffer pH 4.5 and (d) phosphate buffer pH 6.8. 


\begin{tabular}{|c|c|c|c|c|c|c|c|}
\hline \multirow[t]{3}{*}{ Tablet } & \multirow{3}{*}{$\begin{array}{c}\text { Label } \\
\text { amount mg/ } \\
\text { tab }\end{array}$} & \multicolumn{6}{|c|}{ Media } \\
\hline & & \multicolumn{2}{|c|}{$0.1 \mathrm{M} / 0.01 \mathrm{M} \mathrm{HCl}$ (CA / LH) } & \multicolumn{2}{|c|}{ Acetate buffer $\mathrm{pH} 4.5$} & \multicolumn{2}{|c|}{ Phosphate buffer pH 6.8} \\
\hline & & f2 value & Similarity & f2 value & Similarity & f2 value & Similarity \\
\hline LH-MC - 500 & $500 \mathrm{mg}$ & 72.09 & Yes & 67.43 & Yes & 67.58 & Yes \\
\hline LH-LC - 500 & $500 \mathrm{mg}$ & 63.46 & Yes & 65.01 & Yes & 69.84 & Yes \\
\hline CA-MC -500 & $500 \mathrm{mg}$ & 59.84 & Yes & 62.98 & Yes & 68.73 & Yes \\
\hline CA-MC -250 & $250 \mathrm{mg}$ & 61.41 & Yes & 67.45 & Yes & 68.25 & Yes \\
\hline CA-LC -500 & $500 \mathrm{mg}$ & 52.93 & Yes & 55.74 & Yes & 52.65 & Yes \\
\hline CA-LC - 250 & $250 \mathrm{mg}$ & 60.48 & Yes & 70.77 & Yes & 58.91 & Yes \\
\hline
\end{tabular}

\# $f 2$ stands for similarity factor.

\begin{tabular}{|c|c|c|}
\hline Tablet & \%Drug release* & \%Drug permeated ${ }^{*}$ \\
\hline API- LH & $99.80 \pm 0.17$ & $98.2 \pm 0.34$ \\
\hline LH-HC -500 & $97.40 \pm 0.29$ & $96.30 \pm 0.25$ \\
\hline LH-MC -500 & $96.70 \pm 0.46$ & $95.50 \pm 0.22$ \\
\hline LH-LC -500 & $96.90 \pm 0.36$ & $95.80 \pm 0.35$ \\
\hline $\mathrm{API}-\mathrm{CA}$ & $70.01 \pm 0.21$ & $92.40 \pm 0.32$ \\
\hline CA-HC -500 & $75.13 \pm 0.32$ & $90.40 \pm 0.42$ \\
\hline CA-MC -500 & $73.22 \pm 0.46$ & $89.30 \pm 0.33$ \\
\hline CA-LC -500 & $72.50 \pm 0.32$ & $88.10 \pm 0.25$ \\
\hline CA-HC -250 & $74.44 \pm 0.22$ & $91.30 \pm 0.37$ \\
\hline CA-MC -250 & $72.23 \pm 0.37$ & $89.40 \pm 0.27$ \\
\hline CA-LC -250 & $71.32 \pm 0.29$ & $87.90 \pm 0.40$ \\
\hline
\end{tabular}

\# API, LH, CA, HC, MC and LC stands for active pharmaceutical ingredient, levofloxacin hemihydrate, cefuroxime axetil, high cost, medium cost and low cost, respectively.

* Results are expressed as mean $\pm S D$, where $n=3 . S D$ : Standard deviation

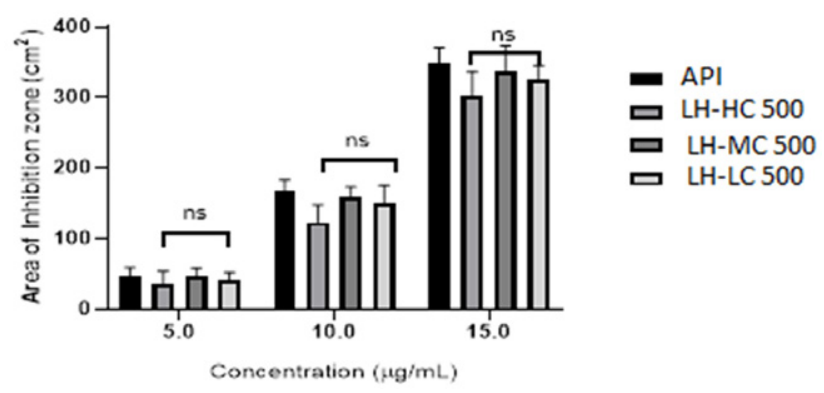

Figure 4: Microbial assay of API and LH 500 tablets against Escherichia coli (ATCC-10536). [ns = non-significant]

analysed using non-parametric Students $t$-test $(p>0.05)$. This can be attributed to the inherent antimicrobial property of drug which is independent of tablet manufacturers, especially when all the formulations are pharmaceutically equivalent. Figures 4-6 represent the relationship between the zone of inhibition and concentration of drug solutions for $\mathrm{LH}$ tablets $(500 \mathrm{mg}), \mathrm{CA}(250 \mathrm{mg}$ and $500 \mathrm{mg}$ ) tablets,

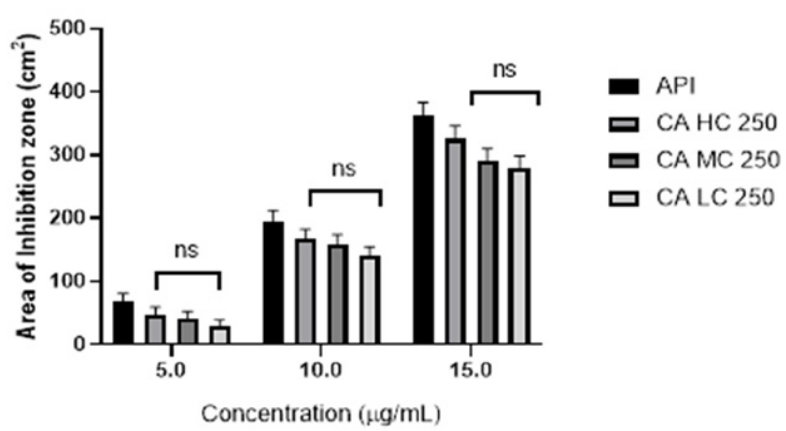

Figure 5: Microbial assay of API and CA 250 tablets against Micrococcus luteus (ATCC-10786). [ns = non-significant]

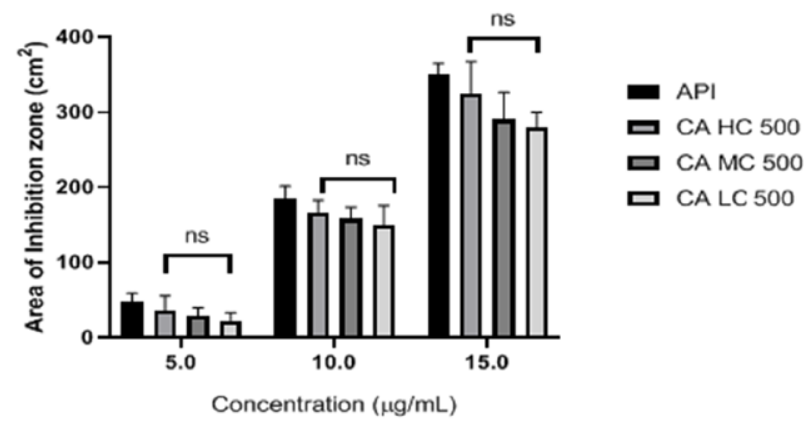

Figure 6: Microbial assay of API and CA 500 tablets against Micrococcus luteus (ATCC-10786). [ns = non-significant]

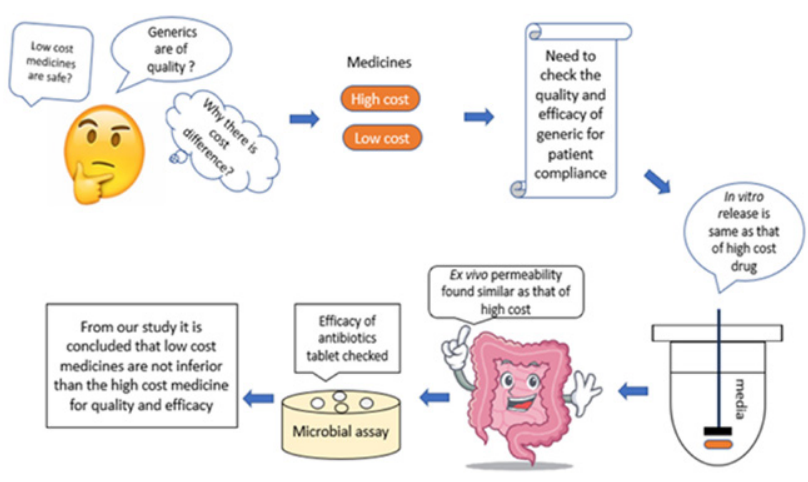

Figure 7: Representative protocol for scrutinizing various antibiotic tablet brands with cost difference. 
respectively along with their respective API. As compared to API, LH as well as CA tablets showed less inhibition as the excipients control the release of active moiety from the tablets. ${ }^{12,14}$

In brief, it was revealed that for BCS class I and II antibiotic tablets, a protocol depicted in Figure 7 can be useful to compare the quality as well as efficacy of various drug brands with different cost. This protocol will be useful tool for assessing low cost alternatives of essential drugs which will assist the regulatory agencies to monitor their manufacturing facility prior to licensing. Additionally, this study helps to build confidence about affordable medicines in general public as well as physicians considering their pharmaceutical quality and safety in patients. However, this study is limited to laboratory testing of few prototype drugs and dosage forms of existing brands. Additionally, the cGMP practices employed during manufacture, transport and storage of medicines needs to be considered.

\section{CONCLUSION}

A common mind-set regarding low cost medicines is that they have compromised quality whereas higher is the price of medicine, better is its quality and efficacy like other conventional products. In this study, we have compared various products of the same drug with varied price range. It was revealed that there is no significant difference between the efficacy of high-cost, medium-cost and economical products of medicines procured from Jan Aushadhi store, a social initiative by Government of India. Quality check for the pharmaceutical evaluation of tablets (IP) and in vitro dissolution along with efficacy check via ex vivo permeability and antimicrobial studies proved that there is no discrepancy between quality as well as efficacy of low cost and other brand tablets. This would be an infallible, rapid protocol, valuable in bringing quality generics in market prior to the clinical trials which suffer due to time lag and legal hassles. This would accelerate the public access and improve perception to the essential drugs at affordable cost, supporting the initiative undertaken by government in the form of Jan Aushadhi.

\section{ACKNOWLEDGEMENT}

Authors are grateful to the Principal of Poona College of Pharmacy for the infrastructure support and encouragement in performing this work.

\section{CONFLICT OF INTEREST}

The authors declare no Conflict of interest.

\section{ABBREVIATIONS}

WHO: World Health Organization; CDSCO: Central Drug Standard Control Organization; CLA: Central Licensing Authority; DCGI: Drug Controller General of India; CTD: Common Technical Document; BCS: Biopharmaceutical Classification System; GIT: Gastrointestinal Tract; LH: Levofloxacin Hemihydrate; CA: Cefuroxime Axetil; JA: Jan Aushadhi; HC: High Cost; MC: Medium Cost; LC: Low Cost; ATCC: American Type Culture Collection; IP: Indian Pharmacopoeia; RS: Reference Solution; NPPA: National Pharmaceutical Pricing Authority; GMP: Good Manufacturing Practices.

\section{REFERENCES}

1. Basak S, Satyanarayana D. Exploring knowledge and perceptions of generic medicines among drug retailers and community pharmacists. Indian J Pharm Sci. 2013;74(6):571-5.

2. Sun HY, Liao HW, Sheng MH, Tai HM, Kuo CH, Sheng WH. Bioequivalence and in vitro antimicrobial activity between generic and brand-name levofloxacin. Diagn Microbiol Infect Dis. 2016;85(3):347-51.

3. Mulakaluri PP. Generic medicines in the Indian scenario: What are we expecting ?. Telangana J Psychiatry. 2017;3:1-3.

4. Sawant AM, Mali DP, Bhagwat DA. Regulatory requirements and drug approval process in India, Europe and US. Pharmaceut Reg Affairs. 2018;7:110.

5. Drugs Controller General (India) Public Notice to All Drugs and Cosmetics Manufacturing Associations and CDSCO Website for public File No. X-11026/011/18-PRO.

6. Official Gazette vide notification number F.28-10/45-H (1), dated the $21^{\text {st }}$ December, 1945 and last amended vide notification number G.S.R. 303 (E) dated the $30^{\text {th }} .2017$.

7. Maruthi HN, Srivatsa HS. Modelling customers' buying behaviour of Jan Aushadhi (Generic Medicines). Indian J of Pharmaceutical Education and Research. 2020;54(1):175-86.

8. Drug Controller General (India) letter to All State/ UT Drug Controllers. Providing a separate shelf/rack for generic medicines in retail shops visible to the consumers. FNO. 18-17/2018-DC. 2018.

9. Central Drug Standard Control Organization. Notice21f_119 Sugam CDSCO. 2016.

10. Central Drug Standard Control Organization. Note: BE-Bioequivalence; CMC-Chemistry and Manufacturing Control; CT-Clinical Trial; SEC-Subject Expert Committee; NOC-No Objection Certificate; IPC-Indian Pharmacopeia Commission. 2018;46.

11. Drug Bank: levofloxacin. 2018. Available from: http://www.drugbank.ca/drugs/ DB00934.

12. Dafale NA, Semwal UP, Agarwal PK, Sharma P, Singh GN. Development and validation of microbial bioassay for quantification of levofloxacin in pharmaceutical preparations. J Pharm Anal. 2015;5(1):18-26.

13. Drug Bank: Cefuroxime. 2018. Available: from: http://www.drugbank.ca/ drugs/DB00934.

14. Dafale NA, Agarwal PK, Semwal UP, Singh GN. Development and validation of microbial bioassay for the quantification of potency of the antibiotic cefuroxime axetil. Anal Methods. 2013;5(1):690-8.

15. Bushra M. Development and validation of a simple UV spectrophotometric method for the determination of cefotaxime sodium in bulk and pharmaceutical formulation. IOSR J Pharm. 2014;4(1):74-7.

16. Patel M, Dharmasi A, Generic VS. Branded: A comparative dissolution study of some commercially available levofloxacin hemihydrate film coated tablets and their pharmacoeconomic evaluations. J Pharm Res Clin Pract. 2014;4:16-22. 
17. U.S. Department of Health and Human Services Food and Drug Administration Centre for Evaluation and Research (CDER). Waiver of in vivo Immediate-Release Solid Oral Bioequivalence Studies for Bioavailability and Biopharmaceutics Classification Dosage Forms based on a Guidance for Industry System. Guidance for Industry: In vitro Metabolism- Mediated Drug-Drug and Transporter- Interaction Studies. Draft Guidance. 2017;1-16.

18. Aruna P, Shruti B, Archana A, Sameer H, Vilasrao J. BCS based biowaivers and their current regulatory issues. Indo Am Pharm Res. 2013;3:6076-82.

19. The Indian Pharmacopoeia Commission. Indian Pharmacopoeia. 2018;1/2:308-9,1119,1544,2426.

20. Food and Drug Administration. Guidance for Industry Bioavailability and Bioequivalence Studies for Orally Administered Drug Products - General Guidance for Industry Bioavailability and Bioequivalence. FDA Guidance. 2002;1-24.

21. Jahangirian $\mathrm{H}$, Haron $\mathrm{J}$, Shah $\mathrm{M}, \mathrm{Al}$ E. Well diffusion method for evaluation of antibacterial activity. Dig J Nanomater Biostructures. 2013;8(3):1263-70.

22. Part II, Section 3, Sub-section (ii) of the Gazette of India. Extraordinary) Government of India Ministry of Chemicals and Fertilizers Department of
Pharmaceuticals National Pharmaceutical Pricing Authority New Delhi. 2019;1-21.

23. AlAmeri MN, Nayuni N, Anil KKG, Perrett D, Tucker A, Johnston A. The differences between the branded and generic medicines using solid dosage forms: In vitro dissolution testing. Results Pharma Sci. 2012;2:1-8.

24. Simionato LD, Petrone L, Baldut M, Bonafede SL, Segall Al. Comparison between the dissolution profiles of nine meloxicam tablet brands commercially available in Buenos Aires, Argentina. Saudi Pharm J. 2018;26(4):578-84.

25. Pawar A, Kamble A, Korake S, Dhapte-Pawar V. Assessing the rationale of FDC containing ofloxacin and azoles: dissolution, permeation and antimicrobial studies. Int J Pharm Pharm Sci. 2019;12(1);36-42.

26. Atul KS, Sanjita DA. Review article on bioavailability and bioequivalence studies. Int J Pharm Tech Res. 2013;5(4):1711-21.

27. Koeppe MO, Cristofoletti R, Fernandes EF, Storpirtis S, Junginger HE, Kopp S, et al. Biowaiver monographs for immediate release solid oral dosage forms: Levofloxacin. J Pharm Sci. 2011;100(5):1628-36.

28. Sruti J, Patra CN, Swain SK, Beg S, Palatasingh HR, Dinda SC, et al. Improvement in dissolution rate of cefuroxime axetil by using poloxamer 188 and neusilin US2. Indian J Pharm Sci. 2013;75(1):67-75.

\section{PICTORIAL ABSTRACT}

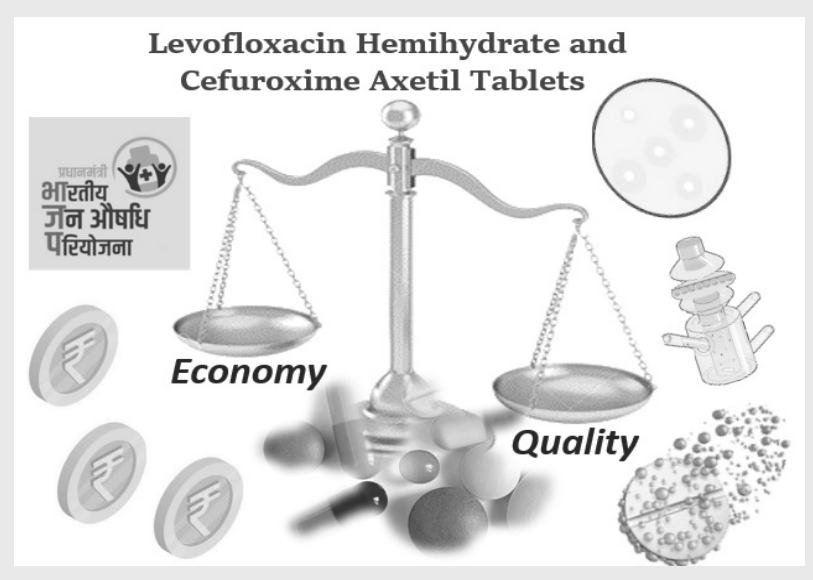

\section{SUMMARY}

Global and national health agencies promote accessibility of affordable medicines to the masses. The Government of India has initiated the Jan Aushadhi stores to offer quality medicines at economic price. The biggest challenge in this attempt is improving the public perception by comparing the quality and efficacy of lowcost medicines. When levofloxacin hemihydrate (LH) and cefuroxime axetil (CA) tablets with price difference including the products from Jan Aushadhi stores were evaluated using pharmacopoeial evaluation tests, ex vivo permeability study and antimicrobial activity, no significant difference between the quality and efficacy of tablets was observed. Thus, the affordable products available in medical stores, especially Jan Aushadhi stores are at par with the branded products and should be prescribed / administered to the patients.

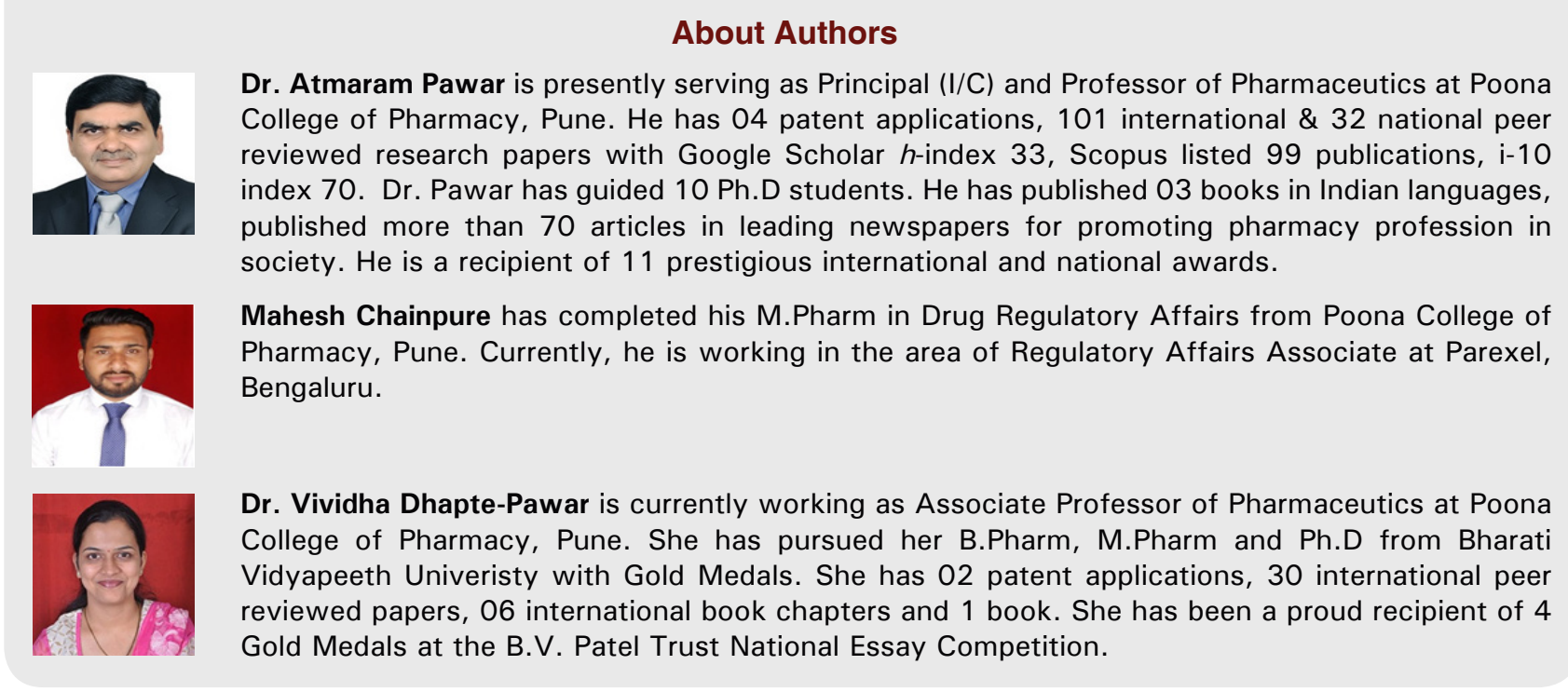

Cite this article: Pawar A, Chainpure M, Dhapte-Pawar V. Paralleling the Quality and Economy of Levofloxacin Hemihydrate and Cefuroxime Axetil Tablets. Indian J of Pharmaceutical Education and Research. 2021;55(1):13645. 